\title{
Surface Morphology of Quail Ovaries in Late Embryonic Stages
}

\author{
By \\ Atsumi UKESHIMA \\ Kumamoto University, College of Medical Science, Kumamoto 862, Japan \\ - Received for Publication, September 11, 1995-
}

\begin{abstract}
Key Words: Ovary, Quail embryo, SEM
Summary: Embryonic quail ovaries were examined with a scanning electron microscope. The same as in many bird species, the quail ovary degenerated on the right side, and normal development occurred only on the left side. The surface of the developing left ovary had a rough appearance. The epithelial cell surface was extremely swollen with many globular protrusions, and the cell borders were lined by ridge-like protrusions. On the other hand, the degenerating right ovarian surface was rather smooth in appearance. Each cell surface had a few short microvilli. Several stomata were found near the border between the ovary and mesonephros in the posterior region of the right ovary. The size and number of stomata were variable, but tended to increase in the later stages. These findings were compared with those in the chick ovary, and a discussion is included.
\end{abstract}

Except for a few species, only the ovary on the left side develops in birds, and the right ovary degenerates during the embryonic period. This is due to failure of cortex formation in the right ovary, because the cortex becomes the functional tissue of the ovary.

In the chick embryo, the degenerating right ovary shows a different profile from the left one (Ukeshima, 1992). The most striking distinction in the chick was the many holes seen on the surface of the right ovary. They increased in number as stages of development progressed. They were continuous with the inner medullary lacunae, and some of the eliminated germ cells exited through these holes (Ukeshima and Fujimoto, 1991; Ukeshima, 1992, 1994). In this short report, we describe the surface of the embryonic quail ovary as observed by SEM and discuss our findings in comparison with previous findings in the chick ovary.

\section{Materials and Methods}

The material used for the present study consisted of ovaries from quail embryos during days 9-15 of incubation. At least three ovaries were examined for each day. Ovaries with adjoining mesonephros were excised from the embryos. They were fixed with $2.5 \%$ glutaraldehyde $(0.1 \mathrm{M}$ phosphate buffer, $\mathrm{pH}$ 7.4) for $1 \mathrm{hr}$, and post-fixed with $1 \%$ osmic acid (0.1 M phosphate buffer, $\mathrm{pH} 7.4)$ for $1 \mathrm{hr}$. After washing with the same buffer, the ovaries were dehydrated in a graded ethanol series, then dried by the critical point drying method. The dried specimens were placed on aluminum stubs and coated with gold-palladium by ion sputter coating. They were then examined with a JEOL JSM-6400F scanning electron microscope.

\section{Results}

Asymmetric quail ovaries with mesonephros attached were found against the abdominal wall. The right ovary was smaller than the left at the stages examined, because of its arrested development. The difference in size became much greater in the later stages (Fig. 1).

The surface of the ovary was composed of mesothelium (peritoneal epithelium). Although the epithelium of the adjacent mesonephros was also composed of mesothelium, the epithelia of these two portions exhibited a different appearance. The mesonephric epithelial cells had a flat surface and few microvilli, except at the edge of each cell, while ovarian epithelial cells exhibited a swollen surface.

\section{Left ovary}

The normally developing left ovary was spindleshaped, and its surface appeared rather rough at low magnification (Fig. 2). At higher magnification, the epithelial cells were usually round or oval, but sometimes fusiform. They were almost all $3-5 \mu \mathrm{m}$ in diameter, but large cells measuring up to $10 \mu \mathrm{m}$ in 

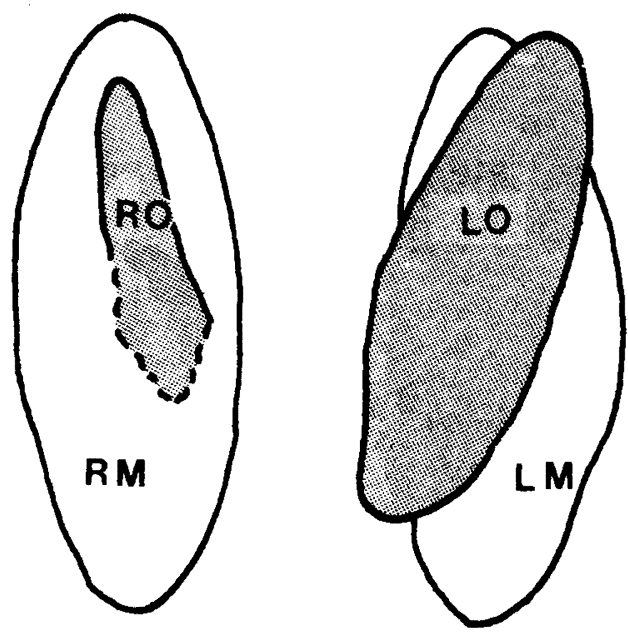

Fig. 1. A drawing of a right and left quail ovary at 13 days of incubation. In contrast to the left ovary (LO), the right ovary (RO) is very small. Its posterior part is flattened, and has an indistinct margin. The dotted line indicates the margin of the ovary. RM, right mesonephros; LM, left mesonephros.

maximum diameter were often seen. The surface of each cell was bulging conspicuously (Fig. 3 ). These observations were almost the same at all stages examined in the present study.

Many protrusions such as microvilli or globular projections were present on the cell surface. In addition, ridge-like protrusions were seen between the cells.

\section{Right ovary}

The right ovary was much smaller in size than the left, particularly in the later stages. The anterior and posterior parts of right ovary showed a different profile. The anterior part was a cylindrical in shape and attached to the mesonephros. The posterior part, on the other hand, was rather flat shape (Fig. 4). The border between ovary and mesonephros was indistinct.

The surface topography of the right ovary, but not the mesonephros, was relatively smooth. Each epithelial cell was oval or fusiform in shape. The cell surface bulging was not as prominent as in the left ovary (Fig. 6). The cells measured $3-5 \mu \mathrm{m}$ in diameter, and the cell surface had a few short microvilli. More microvilli were present along the cell borders, and sometimes ridge-like protrusions were also observed.

In earlier stages, a large cytoplasmic process was sometimes seen on the surface of some cell (Fig. 5). Such cell had a single process, which was thought to represent a cilium.

Several stomata were found along the posterior margin of the right ovary (Fig. 4). They were usually oval in shape and their size was variable. The largest one measured $50 \mu \mathrm{m}$ along its major axis. The stomata were bordered with epithelial cell of the ovarian surface. These cells were irregular or elongated in shape and also had several short microvilli (Fig. 7).

\section{Discussion}

The surface structure of embryonic quail ovaries was examined by SEM, and was found to differ on the right and left sides. The epithelial cells of the degenerating right ovary had fewer protrusions than the left ovary. Cell surface bulging was milder, and microvilli were mainly present at the cell border. This was somewhat similar to the mesonephric surface.

The most striking difference between the right and left was the presence of stomata on the right ovary. No stomata were detected on the left ovary. They were present only at the border between the ovary and mesonephros posterior to the right ovary, and never found on the ovarian surface itself. This is a major difference from the results in the chick (Ukeshima, 1994). In the case of the chick ovary, stomata were present on the ovarian surface itself and their count was higher than in the quail.

In the chick, the stomata on the right ovarian surface were continued to the inner medullary lacunae (Ukeshima, 1992, 1994), and some of the germ cells eliminated into the lacunae exited via the stomata. In the quail ovary, however, the stomata were located at the border of the posterior region of ovary, and no germ cells were found in the stomata. Since tissue sections were not prepared in the present study, it remains unknown whether the stomata observed in the surface view are continuous with the inner medullary lacunae.

Callebaut and coworkers $(1979,1988)$ investigated the presence and function of the pathways (stomata) connecting the medullary lacunae with the peritoneal cavity in the left ovary of quail and chicks. These pathways, however, were located on the posterior side of the ovary. Although the left ovaries were examined in the present study, their posterior side was not examined.

\section{References}

1) Callebaut $M$. The avian ovary is an open organ. A study of the lacunar system. Anat Embryol 1979; 158:103-119.

2) Callebaut $M$, Meeussen $C$ and Nassauw LV. The early development of the lacunar system in the avian ovary. Med Sci Res 1988; 16:1131-1133.

3) Ukeshima A. Scanning electron microscopy of differentiating 
chick ovaries during embryonic period. Zool Sci 1992; 9: 733-739.

4) Ukeshima A. Abandonment of germ cells in the embryonic chick ovary: TEM and SEM studies. Anat Rec 1994; 240:
261-266.

5) Ukeshima A and Fujimoto T. A fine morphological study of germ cells in asymmetrically developing right and left ovaries of the chick. Anat Rec 1991; 230:378-386. 


\section{Explanation of Figures}

Plate I

Fig. 2. Normally developing left ovary with irregular surface. 12 days, M: mesonephros. $\times 170$.

Fig. 3. Higher magnification of the surface of a 12-day left ovary. Most of the cells are round or oval in shape with globular microvilli. Ridge-like protrusions are seen at the cell borders. $\times 4,300$ 

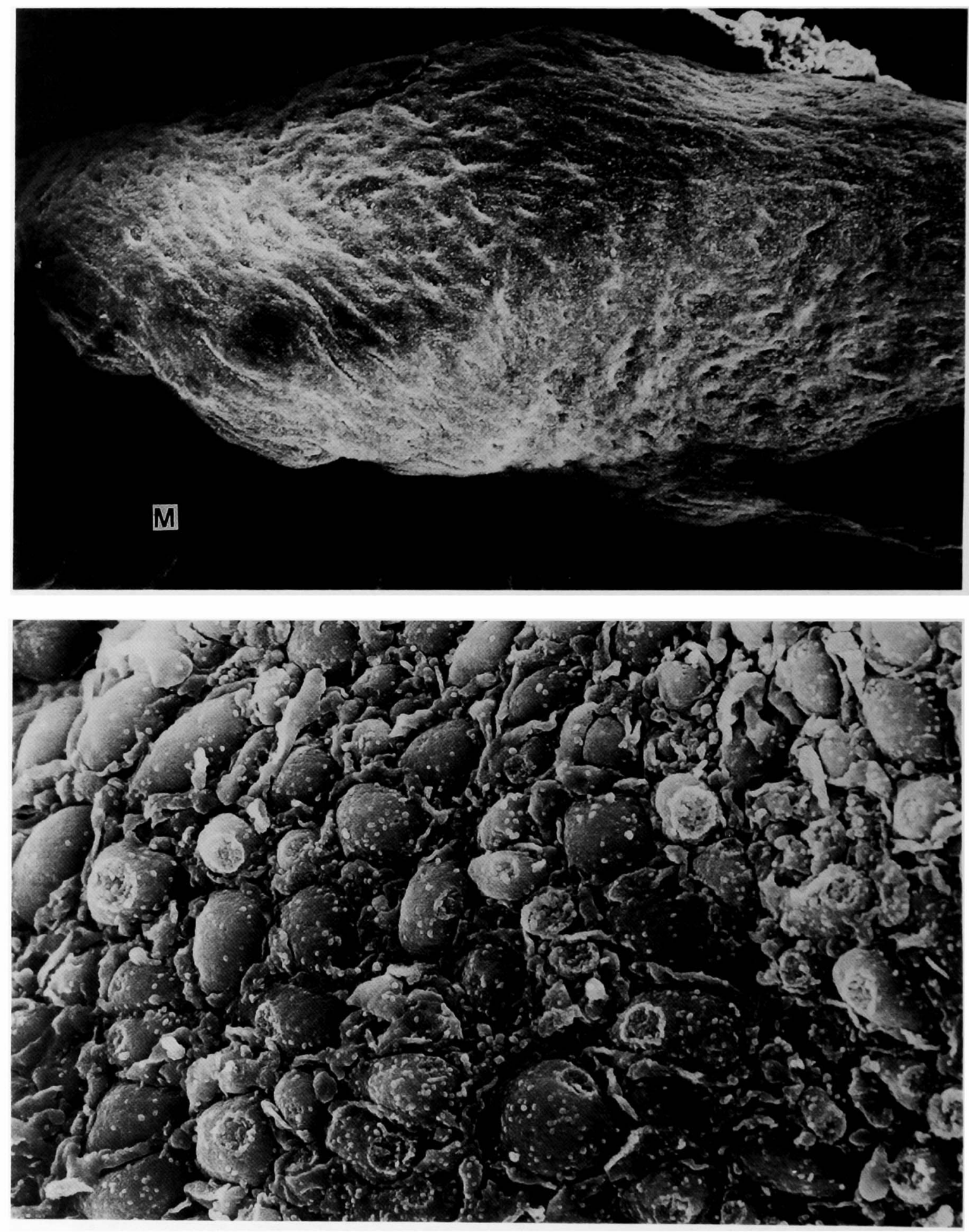


\section{Plate II}

Fig. 4. Low magnification of a 14-day right ovary. Several stomata (arrows) are lined up along the border in the posterior part. The dotted line indicates the outline of the ovary. MS: mesonephros. $\times 275$.

Fig. 5. High magnification of the surface of a 9-day right ovary. Two short cillia are seen in this figure (arrows). $\times 5,000$. 

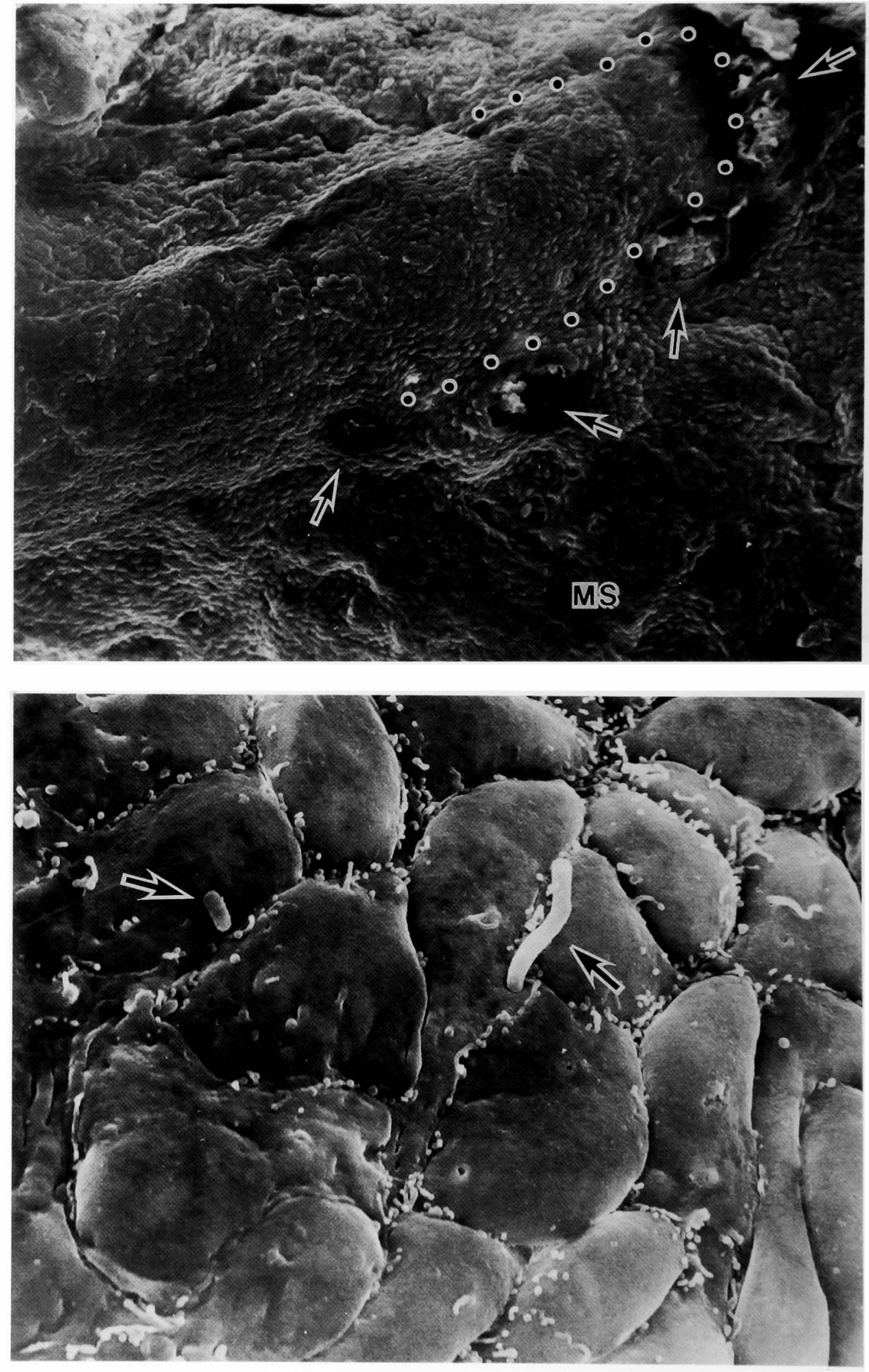


\section{Plate III}

Fig. 6. A surface view of the right ovary at 12 days. Swelling of the epithelial cell surface is not as great as in the left ovary. There are very few microvilli, but the cell borders are lined by many microvilli. $\times 3,200$.

Fig. 7. This figure shows a stoma on the surface of a 13-day ovary. The stoma is lined by elongated epithelial cells. $\times 4,200$. 

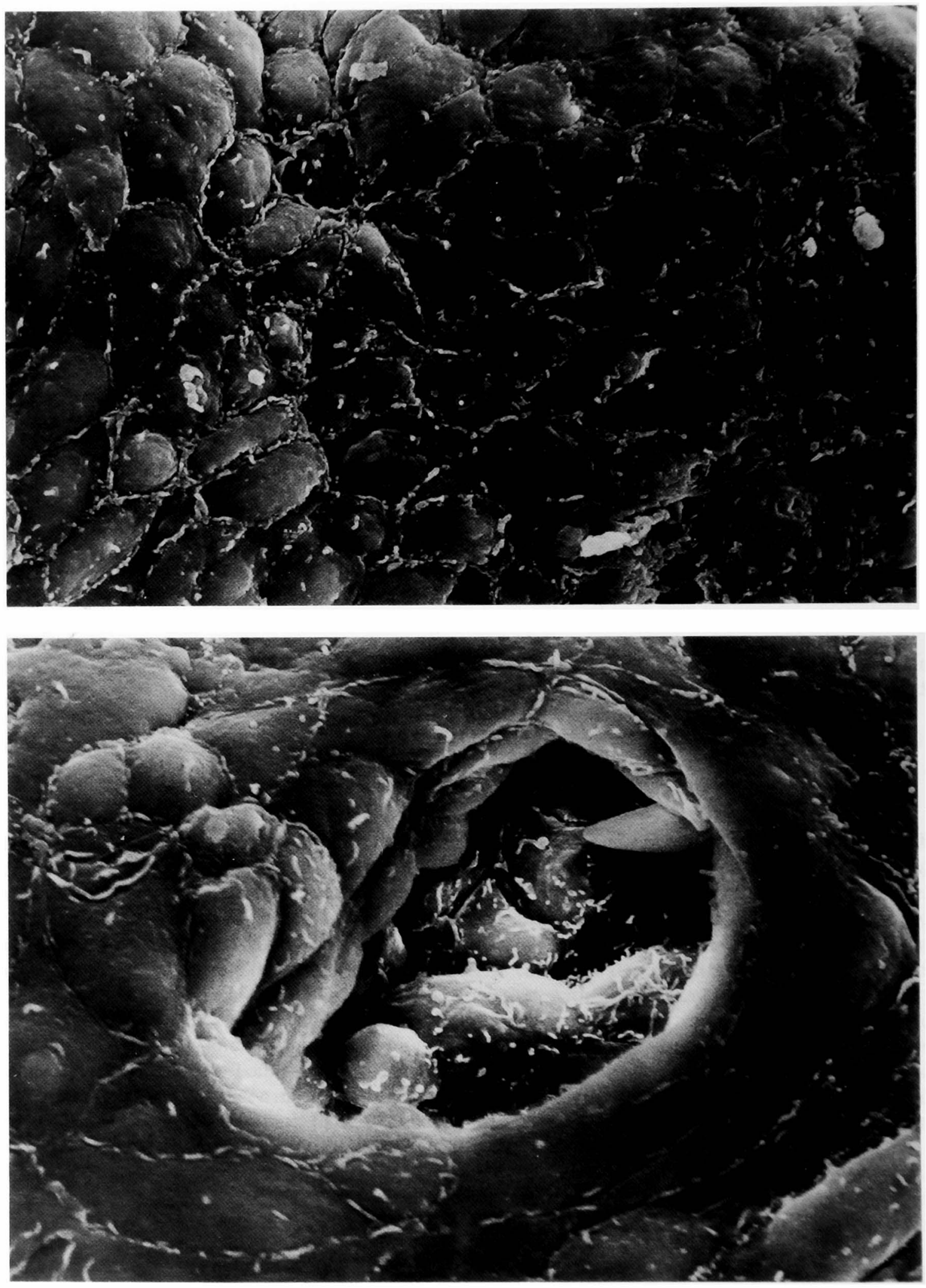